\title{
Long-term results and PSA kinetics after robotic SBRT for prostate cancer: multicenter retrospective study in Korea (Korean radiation oncology group study 15-01)
}

\author{
Younghee Park ${ }^{1}$, Hae Jin Park², Won II Jang ${ }^{3}$, Bae Kwon Jeong ${ }^{4}$, Hun-Jung Kim ${ }^{5}$ and Ah Ram Chang ${ }^{1 *}$
}

\begin{abstract}
Background: To evaluate the treatment outcome and prostate-specific antigen (PSA) change after stereotactic body radiotherapy (SBRT) for localized prostate cancer.

Methods: Patients with localized prostate cancer treated with SBRT at three academic hospitals were enrolled. Treatment was delivered using Cyberknife with dose range from 35 to $37.5 \mathrm{~Gy}$ in 5 fractions. Biochemical failure (BCF) was assessed with Phoenix definition and toxicities were scored with Radiation Therapy Oncology Group (RTOG) toxicity criteria. The PSA kinetics were analyzed in patients who received no androgen deprivation therapy (ADT) and showed no recurrence.
\end{abstract}

Results: Of the total 88 patients, 14 patients (15.9\%) received ADT. After median follow-up of 63.8 months, the 5-year BCF free survival (BCFFS) was 94.7\%. Two patients experienced late grade $\geq 3 \mathrm{Gl}$ toxicities (2.2\%). The median nadir PSA was $0.12 \mathrm{ng} / \mathrm{mL}$ (range, $0.00-2.62 \mathrm{ng} / \mathrm{mL}$ ) and the median time to nadir was 44.8 months (range, $0.40-85.7$ months). Patients who reached nadir before 24 months showed poorer BCFFS than the others. The rate of PSA decline was maximum in the first year after treatment and gradually decreased with time. The pattern of PSA change was significantly different according to the risk groups $(p=0.011)$ with the slope of $-0.139,-0.161$ and $-0.253 \mathrm{ng} / \mathrm{mL} /$ month in low-, intermediate- and high-risk groups, respectively.

Conclusion: SBRT for localized prostate cancer showed favorable efficacy with minimal toxicities. The time to PSA nadir was significantly associated with treatment outcome. PSA revealed rapid initial decline and slower decrease with longer follow-up and the patterns of PSA changes were different according to the risk groups.

Keywords: Prostate cancer, Stereotactic body radiotherapy, PSA, Kinetics

\section{Background}

It has been clearly demonstrated that radiation doseescalation increased the tumor control probabilities in prostate cancer $[1,2]$. However, there are limits for radiation dose-escalation because increased radiation dose resulted in increased probability of normal tissue toxicities.

Studies have found that prostate cancer cells have a low $\alpha / \beta$ ratio of around $1.5[3-5]$. Generally, normal

\footnotetext{
* Correspondence: changaram@schmc.ac.kr

1Department of Radiation Oncology/CyberKnife Center, Soonchunhyang University Seoul Hospital, Daesagwan-ro 59, Youngsan-gu, Seoul 04401, Republic of Korea

Full list of author information is available at the end of the article
}

tissues such as bladder and rectum are known to have $\alpha / \beta$ ratio of 3 and prostate cancer cells are more sensitive to high radiation dose per fraction than normal tissues. Therefore, hypofractionated radiotherapy could deliver higher biological equivalent dose (BED) to cancer cells without increasing the BED to normal tissues. Hypofractionated radiotherapy with dose of 2.4-3.4 Gy per fraction has been evaluated in multiple studies. The efficacy of these moderate hypofractionation was not inferior to conventional fractionation with comparable toxicities [6-8].

Stereotactic body radiotherapy (SBRT), which delivers high dose of radiation in few fractions, is widely used in cancer treatment $[9,10]$. SBRT very precisely delivers

(C) The Author(s). 2018 Open Access This article is distributed under the terms of the Creative Commons Attribution 4.0 International License (http://creativecommons.org/licenses/by/4.0/), which permits unrestricted use, distribution, and 
higher dose per fraction than in moderate hypofractionation and theoretically, SBRT could treat prostate cancer more effectively. Studies have reported the favorable outcome and acceptable toxicities of SBRT for localized prostate cancer [11-14].

Serum PSA is a well-established tumor marker for screening prostate cancer and monitoring response after treatment. The PSA change after radiotherapy has been extensively studied and several parameters such as PSA nadir, time to nadir or PSA velocity have been proposed as predictive factors for treatment outcome [15-18] . However, the PSA kinetics after SBRT have not been fully studied during long-term follow-up period.

In this study, we evaluated the long-term outcome of SBRT for prostate cancer and assessed the PSA kinetics after SBRT.

\section{Methods}

\section{Patients}

Patients with localized prostate cancer treated with SBRT from 2008 through 2014 at three academic hospitals in Korea were enrolled in this study. The inclusion criteria were as follows: 1 ) age $\geq 20$ years; 2) histologically confirmed prostate cancer; 3) no regional lymph node metastases on abdominal CT and no distant metastasis on chest imaging (chest X-ray or CT) and bone scan; 4) SBRT with radical aim; 5) completion of planned SBRT; and 6) follow-up of $\geq 12$ months. Patients with prior history of radiotherapy to pelvis or undergoing SBRT as boost treatment following whole pelvic radiotherapy were excluded. The medical records of included patients were retrospectively reviewed according to the study protocol approved by Korea Radiation Oncology Group (KROG) and the Institutional Review Board of each participant institutions.

\section{Treatment}

SBRT was delivered by Cyberknife (Accuray, Inc., Sunnyvale, CA, USA). Gold fiducial makers were placed in the prostate for real-time motion tracking during treatment. The prescription dose was 35-37.5 Gy in five fractions on consecutive days (QD) or every other day (QOD). Treatment planning was performed using CT scan fused to MRI images. The clinical target volume (CTV) include prostate and seminal vesicles depending on the risks and margin of $3-5 \mathrm{~mm}$ was added to CTV to create the planning target volume. The prescribed dose was normalized to $75-85 \%$ isodose line. Less than $1 \mathrm{~mL}$ of rectum received $36 \mathrm{~Gy}$ and volume of bladder receiving at least 37.5 Gy was $\leq 5 \mathrm{~mL}$.

\section{Follow-up and analysis}

The patients were classified into prognostic risk groups according to the National Comprehensive Cancer
Network (NCCN) guidelines (low-risk: clinical stage $\mathrm{T} 1-\mathrm{T} 2 \mathrm{a}$ and Gleason score $\leq 6$ and PSA $<10 \mathrm{ng} / \mathrm{mL}$, intermediate-risk: clinical stage T2b - T2c or Gleason score 7 or PSA $10-20 \mathrm{ng} / \mathrm{mL}$, high-risk: clinical stage T3a - T4 or, Gleason score $8-10$ or PSA $<20 \mathrm{ng} / \mathrm{mL}$ ). Biochemical failure (BCF) was defined using the Phoenix definition (nadir $+2 \mathrm{ng} / \mathrm{ml}$ ). To assess the accurate effect of SBRT on PSA change, patients who received ADT were excluded from the analysis for PSA kinetics. Additionally, patients who experience recurrence were excluded when evaluating the PSA change in each risk groups to eliminate the compounding effect of PSA elevation in recurred patients. Acute and late toxicities were assessed with Radiation Therapy Oncology Group (RTOG) criteria.

All statistical analyses were performed using SPSS version 18.0 (SPSS Inc., Chicago, IL). BCF free survival (BCFFS) were calculated with Kaplan-Meier Methods. The log-lank test and Cox proportional-hazard model were used for univariate and multivariate analyses. The differences of PSA changes after SBRT between risk groups were evaluated with generalized estimating equations.

\section{Results}

\section{Patient characteristics and treatment}

A total of 88 patients were enrolled in this study. The baseline patient characteristics are shown in Table 1. The median age of patients was 69.5 years (range, $47-81$ years). The median initial PSA was 6.95 (range, 2.05-23.04) $\mathrm{ng} / \mathrm{ml}$ and most patients (98.9\%) had disease confined to prostate (clinical stage $\leq \mathrm{T} 2 \mathrm{c}$ ). Fifty-six $(63.7 \%)$ patients had Gleason score 6 or less. According to the NCCN guidelines, 24 (27.3\%), 50 (56.5\%) and $14(15.9 \%)$ patients were in low-, intermediate- and high-risk group, respectively. Fourteen patients (15.9\%) received neoadjuvant, concurrent or adjuvant $\mathrm{ADT}$. Most of the patients (71.6\%) received $37.5 \mathrm{~Gy}$ and the treatment was delivered on consecutive days in 54 $(62.5 \%)$ patients (Table 2).

\section{Treatment outcome and PSA kinetics Treatment outcome in all patients}

After median follow-up of 63.8 months (range 12.1109.5 months), 4 patients experienced a biochemical relapse (2 low-, 1 intermediate- and 1 high-risk group). One of the recurred patients received concurrent ADT. The actuarial 5-year BCFFS was $94.7 \%$ (Fig. 1-a). The median nadir PSA was $0.12 \mathrm{ng} / \mathrm{mL}$ (range, $0.00-2.62$ $\mathrm{ng} / \mathrm{mL}$ ) and median time to nadir was 44.8 months (0.40-85.7 months) in all patients.

\section{PSA kinetics in no ADT group}

To exclude the effect of ADT on the PSA change, we excluded 14 patients who received ADT in the analysis for PSA kinetics. In 74 patients who did not received ADT, 
Table 1 Patient characteristics

\begin{tabular}{|c|c|c|}
\hline & $n$ & $\%$ \\
\hline \multicolumn{3}{|l|}{ age, years } \\
\hline median & 69.5 & \\
\hline range & $47-81$ & \\
\hline \multicolumn{3}{|c|}{ initial PSA, ng/ml } \\
\hline median & 6.95 & \\
\hline range & $2.05-23.04$ & \\
\hline \multicolumn{3}{|c|}{ preCK PSA, ng/ml } \\
\hline median & 6.65 & \\
\hline range & $0.01-21.62$ & \\
\hline \multicolumn{3}{|l|}{ T stage } \\
\hline $1 c$ & 27 & 30.7 \\
\hline $2 a$ & 19 & 21.6 \\
\hline $2 b$ & 14 & 15.9 \\
\hline $2 c$ & 27 & 30.7 \\
\hline $3 a$ & 1 & 1.1 \\
\hline \multicolumn{3}{|l|}{ Gleason score } \\
\hline$\leq 6$ & 56 & 63.7 \\
\hline 7 & 20 & 22.7 \\
\hline$\geq 8$ & 12 & 13.6 \\
\hline \multicolumn{3}{|l|}{ Risk group } \\
\hline low & 24 & 27.3 \\
\hline intermediate & 50 & 56.5 \\
\hline high & 14 & 15.9 \\
\hline \multicolumn{3}{|l|}{ ADT } \\
\hline no & 74 & 84.1 \\
\hline yes & 14 & 15.9 \\
\hline \multicolumn{3}{|c|}{ Prostate volume, $\mathrm{ml}$} \\
\hline median & 40.0 & \\
\hline range & $12.0-94.8$ & \\
\hline \multicolumn{3}{|l|}{ Initial IPSS } \\
\hline Median & 3 & \\
\hline range & $0-15$ & \\
\hline
\end{tabular}

Abbreviations: PSA Prostate-specific antigen, $A D T$ Androgen deprivation therapy, IPSS International prostate symptom score

the median nadir PSA was $0.15 \mathrm{ng} / \mathrm{mL}(0.01-2.62 \mathrm{ng} / \mathrm{mL})$ and median time to nadir was 47.3 months (1.2-85.7 months). The nadir PSA value did not show any significant association with treatment outcome in these patients. However, patients who reached nadir PSA 24 months after SBRT showed better BCFFS rate than the other patients ( $p=0.001$, Fig. 1-b).

To evaluate the PSA declining kinetics after SBRT excluding the effect of recurrence, additional 3 patients with recurrence were excluded. In the remaining $71 \mathrm{pa}-$ tients, the median nadir PSA value was $0.075,0.23$ and $0.13 \mathrm{ng} / \mathrm{mL}$ and median time to nadir was $53.4,46.4$ and
Table 2 Summary of SBRT dose and treatment schedule

\begin{tabular}{lll}
\hline & $\mathrm{n}$ & $\%$ \\
\hline Total dose (Gy) & 2 & 2.3 \\
35.00 & 22 & 25.0 \\
36.25 & 1 & 1.1 \\
36.50 & 63 & 71.6 \\
37.50 & & \\
Treatment schedule & 55 & 62.5 \\
QD & 33 & 37.5 \\
QOD & 33 \\
\hline
\end{tabular}

Abbreviations: $Q D$ Daily treatment, $Q O D$ Every-other-day treatment

50.1 months after SBRT in low-, intermediate- and high-risk groups, respectively. There were no statistically significant differences in nadir value or time to nadir according to the risk groups. The benign PSA bounce was observed in 25 patients $(35.2 \%)$ and the frequency of PSA bounce was not associated with risk groups or Gleason score. The median time to bounce was 11.0 months (range, 2.9-38.5 months) after SBRT, and the median height of PSA bounce was $0.53 \mathrm{ng} / \mathrm{ml}$ (range, $0.24-2.62 \mathrm{ng} / \mathrm{ml})$. The rate of PSA decline was maximum in the first year after treatment and decreased with time. The median slope of PSA decline was -0.47 , -0.27 , and $-0.18 \mathrm{ng} / \mathrm{mL} / \mathrm{month}$ in the 1,2 , and 3 year after SBRT, respectively (Fig. 2). The slope of PSA change was significantly different according to the risk groups $(p=0.017)$ with the median values of -0.139 , 0.161 and $-0.253 \mathrm{ng} / \mathrm{mL} / \mathrm{month}$ in low-, intermediateand high-risk groups, respectively. The total Gleason score or primary Gleason score did not affect the rate of PSA change after SBRT.

\section{Toxicity}

There were no grade $\geq 3$ acute gastrointestinal (GI) or genitourinary (GU) toxicity. (Table 3 ) No patients experienced grade $\geq 3$ late $\mathrm{GU}$ toxicity but grade $\geq 3$ late $\mathrm{GI}$ toxicity occurred in 2 patients (2.2\%). One patient had grade 3 rectal bleeding and one developed grade 4 recto-urethral fistula, which required colostomy and cystostostomy at 19 months after SBRT. The treatment schedule (every-other-day treatment vs. daily treatment) did not affect the rate of acute or late toxicities.

\section{Discussion}

In this study, we found excellent treatment outcome with low rate of treatment related toxicity after SBRT in localized prostate cancer. The favorable outcomes of SBRT and acceptable toxicity rates have been reported in previous studies with follow-up of 2-3 years [11-13]. In our results, we only included patients with follow-up of more than 1 year and the median follow-up duration was 64.5 months providing favorable long-term results. 


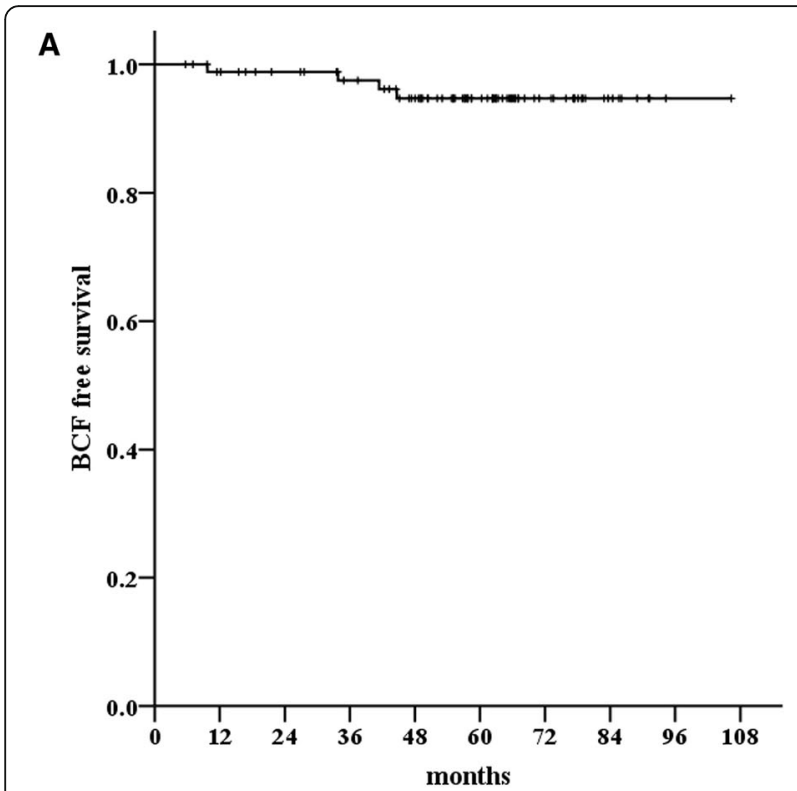

B

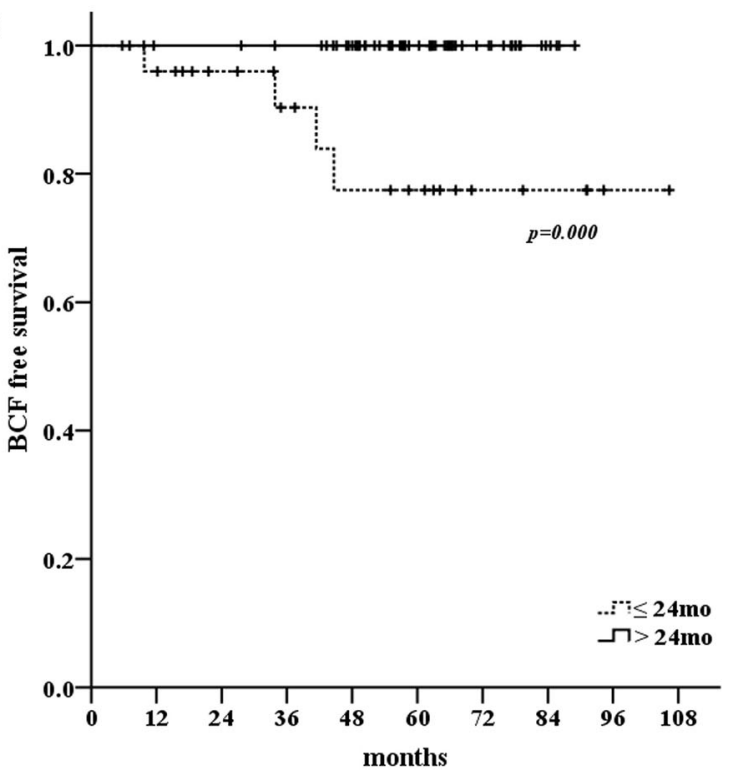

Fig. 1 The biochemical failure-free survival in all patients (a) and according to the time to nadir (b)

Previously, two studies have reported long-term outcomes comparable to our study $[19,20]$. Freeman et al. reported 5 -year outcome of SBRT with 35-36.25 Gy / 5 fractions in 41 low-risk prostate cancers patients. The biochemical progression-free survival rate was $93 \%$, which they suggest comparable to brachytherapy or surgery with less toxicity profiles. Katz et al. also reported the outcomes of a large study consisting of 304 patients with median follow-up of 60 months [20]. They performed the SBRT at 2 dose levels, $35 \mathrm{~Gy}$ or $36.25 \mathrm{~Gy}$ in 5 fractions, and found no effect of total dose on the treatment outcome or PSA nadir levels. Late urinary or rectal complication was more frequent in patients treated to $36.25 \mathrm{~Gy}$ but the difference was not statistically significant. They included all risk groups and the 5-year biochemical recurrence-free survival was $97,90.7$ and $74.1 \%$ for low-, intermediate- and high-risk patients, respectively.

Although SBRT has been accepted as a proper treatment option for low- to intermediate-risk prostate cancer patients, the efficacy in high-risk patients is unknown. We included 14 (15.9\%) high-risk patients and could not find any significant difference in the outcome among different risk groups. The treatment outcome of high-risk patients in our study (3- and 5-year BCCFS, 100 and 91.7\%) which were remarkably better than in study by Katz et al. In another study [21], Katz et al. reported the long-term outcome of SBRT for high-risk patients comparing the outcome of SBRT alone with pelvic radiation followed by SBRT boost and found no difference in outcome between two treatment groups. They used same radiation doses with previous study (35 and $36.25 \mathrm{~Gy}$ ), and their outcome was still relatively poor (6-year biochemical disease-free survival, 69\%) compared to results of other risk group. Again in that study, they found no dose response in both treatment groups. Oliai et al. reported the outcome of SBRT for all risk group of prostate cancer patients [13]. A total of 70 patients received SBRT at 3 levels of 35, 36.25 and 37.5 Gy in 5 fraction and outcomes of high dose (37.5 Gy) and low dose (36.25 and $35 \mathrm{Gy)}$ groups were compared. As a result, they found a dose response in intermediate- and high-risk patients (3-year freedom from biochemical failure, $100 \%$ in high dose vs. $72 \%$ in low dose group, $p=0.0363$ ). We also used the same high dose of 37.5 Gy as in a study of Oliai et al. in most high-risk patients (12 of 14 patients, $85.7 \%$ ). The treatment outcome of high-risk patients in our study (3- and 5-year BCFFS, 100 and 91.7\%) was also comparable to the high dose group of Oliai study. Additionally, the poor outcome of high-risk patient in a study of Katz et al. was similar to the outcome of low dose group of Oliai study. These results suggest that although SBRT showed favorable results in prostate cancer, higher dose of SBRT is needed and the dose as high as 37.5 Gy used in our study would be effective for high-risk groups. There has been dose escalation SBRT studies for low- to intermediate-risk groups and dose escalation to 50 Gy has been completed without dose limiting toxicity [22, 23]. A large and well-designed prospective study would be needed to find the optimal dose for high-risk prostate cancer.

The nadir PSA has been suggested as a significant prognostic marker in conventional fractionation radiotherapy by numerous studies and they proposed $0.2-1.5 \mathrm{ng} / \mathrm{mL}$ as a cut-off value for predicting the outcome $[15,24,25]$. Ray et al. reported PSA nadir and time to nadir were significant predictor for disease-free 


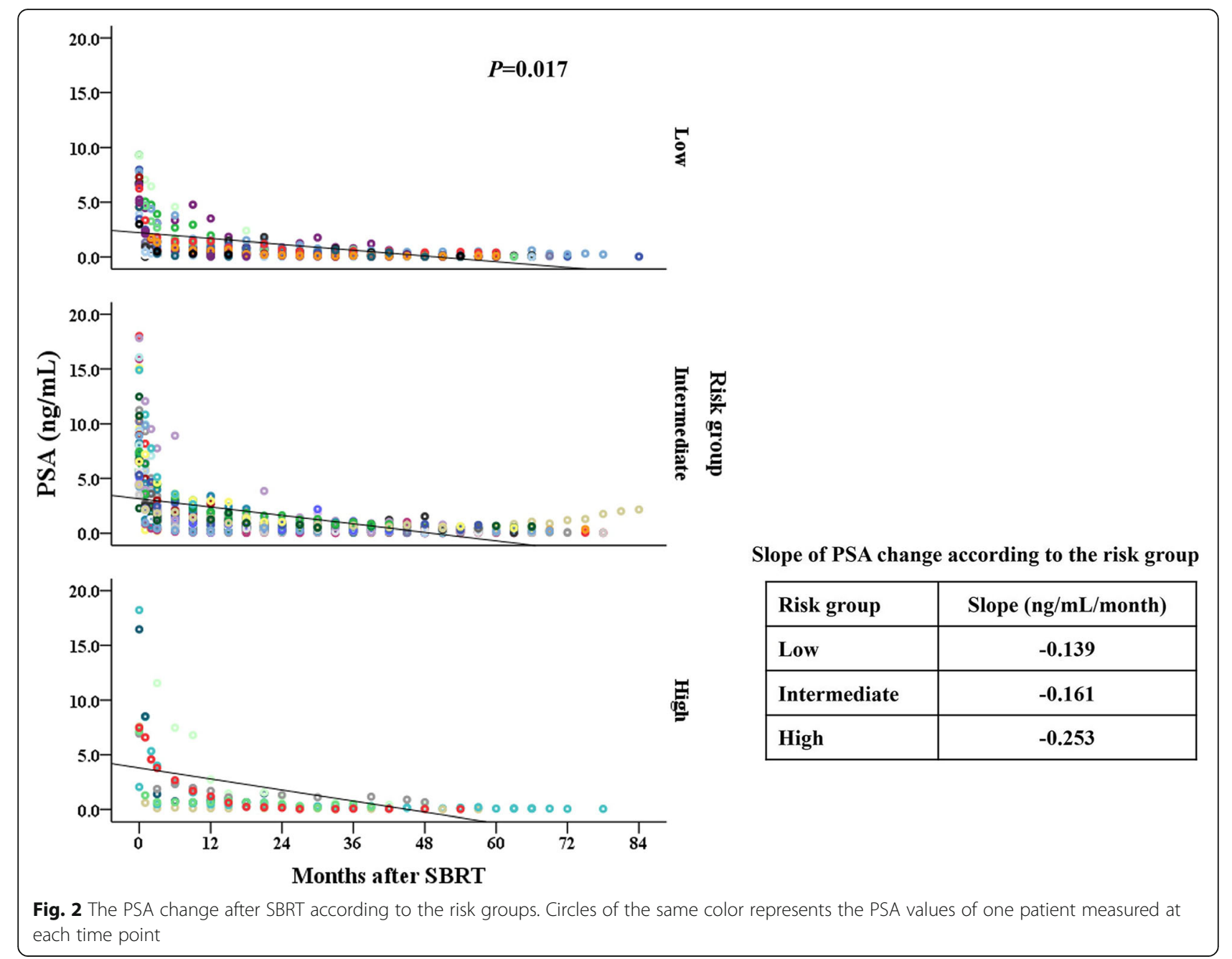

survival and distant metastasis-free survival [18]. They categorized the nadir PSA into 4 levels, $<0.50,0.50-0.99$, $1.0-1.99$ and $\geq 2.00 \mathrm{ng} / \mathrm{mL}$ and found better survival with lower nadir PSA level. However, in our study, the nadir PSA did not show any association with BCFFS. The median value of nadir PSA in our study was $0.12 \mathrm{ng} / \mathrm{mL}$ and more than half of the patients $(n=54,61.4 \%)$ reached nadir less than $0.2 \mathrm{ng} / \mathrm{mL}$ which is significantly lower than the reported nadir value of conventional radiotherapy.

Table 3 Acute and late toxicity

\begin{tabular}{lllllll}
\hline & & Gl & & & GU \\
& Grade & $\mathrm{n}$ & $\%$ & Grade & $\mathrm{n}$ & $\%$ \\
\hline Acute Toxicity & 1 & 32 & 36.4 & 1 & 43 & 48.9 \\
& 2 & 5 & 5.7 & 2 & 8 & 9.1 \\
Late Toxicity & 1 & 10 & 11.4 & 1 & 27 & 30.7 \\
& 2 & 1 & 1.1 & 2 & 2 & 2.3 \\
& $\geq 3$ & $2^{\text {a }}$ & 2.3 & & &
\end{tabular}

Abbreviations: GI Gastrointestinal, GU Genitourinary

${ }^{\text {a }}$ Rectal bleeding and recto-urethral fistula
Previously, Kishan et al. reported that nadir PSAs after SBRT or HDR brachytherapy were significantly lower than IMRT [26]. Anwar et al. also reported the lower PSA nadir after SBRT than conventional fractionation radiotherapy [27]. Therefore, conventional threshold value for nadir to predict the outcome may not be useful in SBRT, which achieves much less nadir PSA.

After SBRT, the PSA showed maximum decline in the first year after SBRT and gradual decline continued until the last follow-up. At the same time, the time to nadir PSA also increased with longer follow-up. Similar PSA kinetics after SBRT have been reported in several studies [26-28]. They all reported the initial rapid decline of PSA followed by a prolonged slow decay. They suggested that rapid decline of PSA in initial phase is caused by destruction of malignant cells and further prolonged decrease reflects the decline of PSA produced by benign tissues. In our study, the time to nadir PSA showed significant association with BCFFS. Patient who achieved nadir PSA after 24 months showed better prognosis than those before 24 months. Fourteen patients who received 
neoadjuvant, concurrent or adjuvant ADT were excluded in this analysis to exclude the effect of ADT on the outcomes. In conventional fraction radiotherapy, Ray et al. reported the similar results [18]. They found that longer time to nadir PSA significantly associated with improved biochemical and distant failure-free survival. Generally, it is well known that prostate cancer shows heterogeneity in malignant potential and multiple Gleason grade can be found in the same specimen $[29,30]$. Therefore, prostate cancer cells with diverse malignant potential might have diverse $\alpha / \beta$ ratio. As shown in our study with two-phase decline of PSA, the prostate cancer cells are assumed to have different destruction pattern after SBRT. Cancer cells with more malignant potential could be removed early after SBRT and less aggressive cancer cells with normal prostate cells could show more protracted death. Therefore, longer time to nadir PSA could reflect the presence of more indolent cancer cells and this could have resulted in better prognosis. The various reported $\alpha / \beta$ ratio values of prostate cancer could have resulted from this heterogeneity of prostate cancer [3-5].

We tried to evaluate PSA changes in different risk groups after SBRT. To eliminate the effect of recurrence on PSA decline, total number of non-recurred 71 patients were included in this analysis. As a result, the PSA change was significantly different according to the risk groups. High-risk group showed steepest slope of PSA decline. Total Gleason score, or primary grade alone, did not show any significant differences in PSA slope. Although we failed to find any relationship between risk groups and prognosis after long-term follow-up, we suggest that different risk groups have different ratio of more malignant and more indolent cancer cells and show different PSA decay pattern, which were well incorporated in the prognosis of prostate cancer. Further study in a prospective and well-stratified way regarding the heterogeneity of malignant potential in all the prostate cancer risk groups and PSA kinetics after SBRT can validate our hypothesis.

Our study has an inherent limitation that it is retrospective study. However, we included large numbers of patients from 3 academic institutions and provided clinical outcomes and changes of PSA values after longer follow-up (63.8 months).

\section{Conclusions}

In conclusion, SBRT for prostate cancer is effective and safe even in all risk group patients. The longer time to nadir PSA was predictive for better outcome. PSA showed rapid initial decrease and continued gradual decline with longer follow-up and velocity of PSA decline was different according to the risk groups. These PSA kinetics including nadir value and time to nadir, which is distinctive from conventional radiotherapy, should be considered during the follow-up periods after SBRT for prostate cancer.

\section{Abbreviations}

ADT: Androgen deprivation therapy; BCF: Biochemical failure; BCFFS: BCF free survival; BED: Biological equivalent dose; CTV: Clinical target volume; KROG: Korea Radiation Oncology Group; NCCN: National Comprehensive Cancer Network; PSA: Prostate-specific antigen; QD: Once a day; QOD: Every other day; RTOG: Radiation Therapy Oncology Group; SBRT: Stereotactic body radiotherapy

\section{Acknowledgements}

Not applicable.

Funding

This work was supported by the Soonchunhyang University Research Fund.

\section{Availability of data and materials}

All data generated or analysed during this study are included in this published article.

\section{Authors' contributions}

YP analyzed the data and drafted the manuscript. HJP, WIJ, BKJ and HJK collected data. ARC designed this study, interpreted the results and revised the manuscript. All authors read and approved the final manuscript.

Ethics approval and consent to participate

This study was approved by Korea Radiation Oncology Group (KROG) and the Institutional Review Board of each participant institutions.

Consent for publication

Not applicable.

Competing interests

The authors declare that they have no competing interests.

\section{Publisher's Note}

Springer Nature remains neutral with regard to jurisdictional claims in published maps and institutional affiliations.

\section{Author details}

'Department of Radiation Oncology/CyberKnife Center, Soonchunhyang University Seoul Hospital, Daesagwan-ro 59, Youngsan-gu, Seoul 04401, Republic of Korea. ${ }^{2}$ Department of Radiation Oncology, Hanyang University College of Medicine, Seoul, Republic of Korea. ${ }^{3}$ Department of Radiation Oncology, Korea Institute of Radiological and Medical Sciences, Seoul, Republic of Korea. ${ }^{4}$ Department of Radiation Oncology, Gyeongsang National University School of Medicine and Gyeongsang National University Hospital, Jinju, Republic of Korea. ${ }^{5}$ Department of Radiation Oncology, Inha University Hospital, Incheon, Republic of Korea.

Received: 10 October 2018 Accepted: 12 November 2018

Published online: 23 November 2018

\section{References}

1. Dearnaley DP, Jovic G, Syndikus I, Khoo V, Cowan RA, Graham JD, Aird EG, Bottomley D, Huddart RA, Jose CC, et al. Escalated-dose versus control-dose conformal radiotherapy for prostate cancer: long-term results from the MRC RT01 randomised controlled trial. Lancet Oncol. 2014;15:464-73.

2. Storey MR, Pollack A, Zagars G, Smith L, Antolak J, Rosen I. Complications from radiotherapy dose escalation in prostate cancer: preliminary results of a randomized trial. Int J Radiat Oncol Biol Phys. 2000;48:635-42.

3. Brenner DJ, Martinez AA, Edmundson GK, Mitchell C, Thames HD, Armour EP. Direct evidence that prostate tumors show high sensitivity to fractionation (low alpha/beta ratio), similar to late-responding normal tissue. Int J Radiat Oncol Biol Phys. 2002;52:6-13.

4. Brenner DJ, Hall EJ. Fractionation and protraction for radiotherapy of prostate carcinoma. Int J Radiat Oncol Biol Phys. 1999:43:1095-1/101.

5. Fowler JF. The radiobiology of prostate cancer including new aspects of fractionated radiotherapy. Acta Oncol. 2005;44:265-76.

6. Lee WR, Dignam JJ, Amin MB, Bruner DW, Low D, Swanson GP, Shah AB, D'Souza DP, Michalski JM, Dayes IS, et al. Randomized phase III noninferiority study comparing two radiotherapy fractionation schedules in patients with low-risk prostate Cancer. J Clin Oncol. 2016;34:2325-32. 
7. Lukka H, Hayter C, Julian JA, Warde P, Morris WJ, Gospodarowicz M, Levine M, Sathya J, Choo R, Prichard H, et al. Randomized trial comparing two fractionation schedules for patients with localized prostate cancer. J Clin Oncol. 2005;23:6132-8.

8. Incrocci L, Wortel RC, Alemayehu WG, Aluwini S, Schimmel E, Krol S, van der Toorn PP, Jager H, Heemsbergen W, Heijmen B, Pos F. Hypofractionated versus conventionally fractionated radiotherapy for patients with localised prostate cancer (HYPRO): final efficacy results from a randomised, multicentre, open-label, phase 3 trial. Lancet Oncol. 2016;17:1061-9.

9. Kollar L, Rengan R. Stereotactic body radiotherapy. Semin Oncol. 2014;41:776-89.

10. Timmerman RD, Kavanagh BD, Cho LC, Papiez L, Xing L. Stereotactic body radiation therapy in multiple organ sites. J Clin Oncol. 2007;25:947-52.

11. King CR, Brooks JD, Gill H, Presti JC. Long-term outcomes from a prospective trial of stereotactic body radiotherapy for low-risk prostate Cancer. Int J Radiat Oncol Biol Phys. 2012;82:877-82.

12. Chen LN, Suy S, Uhm S, Oermann EK, Ju AW, Chen V, Hanscom HN, Laing S, Kim JS, Lei S, et al. Stereotactic body radiation therapy (SBRT) for clinically localized prostate cancer: the Georgetown University experience. Radiat Oncol. 2013;8:58

13. Oliai C, Lanciano R, Sprandio B, Yang J, Lamond J, Arrigo S, Good M, Mooreville M, Garber B, Brady LW. Stereotactic body radiation therapy for the primary treatment of localized prostate cancer. J Radiat Oncol. 2013;2:63-70.

14. Alongi F, Mazzola R, Fiorentino A, Corradini S, Aiello D, Figlia V, Gregucci F, Ballario R, Cavalleri S, Ruggieri R. Phase II study of accelerated Linac-based SBRT in five consecutive fractions for localized prostate cancer. Strahlenther Onkol. 2018. [Epub ahead of print].

15. Zietman AL, Tibbs MK, Dallow KC, Smith CT, Althausen AF, Zlotecki RA, Shipley WU. Use of PSA nadir to predict subsequent biochemical outcome following external beam radiation therapy for T1-2 adenocarcinoma of the prostate. Radiother Oncol. 1996;40:159-62.

16. Pollack A, Zagars GK, Antolak JA, Kuban DA, Rosen II. Prostate biopsy status and PSA nadir level as early surrogates for treatment failure: analysis of a prostate cancer randomized radiation dose escalation trial. Int J Radiat Oncol Biol Phys. 2002;54:677-85.

17. Shi Z, Pinnock CB, Kinsey-Trotman S, Borg M, Moretti KL, Walsh S, Kopsaftis T. Prostate-specific antigen (PSA) rate of decline post external beam radiotherapy predicts prostate cancer death. Radiother Oncol. 2013;107:129-33.

18. Ray ME, Thames HD, Levy LB, Horwitz EM, Kupelian PA, Martinez AA, Michalski JM, Pisansky TM, Shipley WU, Zelefsky MJ, et al. PSA nadir predicts biochemical and distant failures after external beam radiotherapy for prostate cancer: a multi-institutional analysis. Int J Radiat Oncol Biol Phys. 2006;64:1140-50.

19. Freeman DE, King CR. Stereotactic body radiotherapy for low-risk prostate cancer: five-year outcomes. Radiat Oncol. 2011;6:3.

20. Katz AJ, Santoro M, Diblasio F, Ashley R. Stereotactic body radiotherapy for localized prostate cancer: disease control and quality of life at 6 years. Radiat Oncol. 2013;8:118

21. Katz A, Kang J. Stereotactic body radiotherapy with or without external beam radiation as treatment for organ confined high-risk prostate carcinoma: a six year study. Radiat Oncol. 2014;9:1.

22. Boike TP, Lotan Y, Cho LC, Brindle J, DeRose P, Xie XJ, Yan J, Foster R, Pistenmaa D, Perkins A, et al. Phase I dose-escalation study of stereotactic body radiation therapy for low- and intermediate-risk prostate cancer. J Clin Oncol. 2011;29:2020-6.

23. Kotecha R, Djemil T, Tendulkar RD, Reddy CA, Thousand RA, Vassil A, Stovsky M, Berglund RK, Klein EA, Stephans KL. Dose-escalated stereotactic body radiation therapy for patients with intermediate- and high-risk prostate Cancer: initial dosimetry analysis and patient outcomes. Int J Radiat Oncol Biol Phys. 2016;95:960-4.

24. Lee WR, Hanlon AL, Hanks GE. Prostate specific antigen nadir following external beam radiation therapy for clinically localized prostate cancer: the relationship between nadir level and disease-free survival. J Urol. 1996;156:450-3.

25. Zelefsky MJ, Shi W, Yamada Y, Kollmeier MA, Cox B, Park J, Seshan VE. Postradiotherapy 2-year prostate-specific antigen nadir as a predictor of long-term prostate cancer mortality. Int J Radiat Oncol Biol Phys. 2009;75:1350-6.

26. Kishan AU, Wang PC, Upadhyaya SK, Hauswald H, Demanes DJ, Nickols NG, Kamrava M, Sadeghi A, Kupelian PA, Steinberg ML, et al. SBRT and HDR brachytherapy produce lower PSA nadirs and different PSA decay patterns than conventionally fractionated IMRT in patients with low- or intermediaterisk prostate cancer. Pract Radiat Oncol. 2016;6:268-75.
27. Anwar M, Weinberg V, Chang AJ, Hsu IC, Roach M 3rd, Gottschalk A. Hypofractionated SBRT versus conventionally fractionated EBRT for prostate cancer: comparison of PSA slope and nadir. Radiat Oncol. 2014;9:42.

28. Kole TP, Chen LN, Obayomi-Davies O, Kim JS, Lei S, Suy S, Dritschilo A, Collins SP. Prostate specific antigen kinetics following robotic stereotactic body radiotherapy for localized prostate cancer. Acta Oncol. 2015;54:832-8.

29. Aihara M, Wheeler TM, Ohori M, Scardino PT. Heterogeneity of prostate cancer inradical prostatectomy specimens. Urology. 1994;43:60-6.

30. Ruijter ET, van de Kaa CA, Schalken JA, Debruyne FM, Ruiter DJ. Histological grade heterogeneity in multifocal prostate cancer. Biological and clinical implications. J Pathol. 1996;180:295-9.

\section{Ready to submit your research? Choose BMC and benefit from:}

- fast, convenient online submission

- thorough peer review by experienced researchers in your field

- rapid publication on acceptance

- support for research data, including large and complex data types

- gold Open Access which fosters wider collaboration and increased citations

- maximum visibility for your research: over $100 \mathrm{M}$ website views per year

At BMC, research is always in progress.

Learn more biomedcentral.com/submissions 